\title{
Roadblocks to health reform in China
}

$\mathrm{T}$ wo years after China launched a sweeping US\$130-billion health care reform plan, the country faces huge obstacles to progress in what's been described as the world's largest health care experiment.

The plan centres on quickly reforming hospital management while delivering universal access to primary health care through national insurance schemes. But roadblocks have arisen, according to new research presented at the annual world congress of the International Health Economics Association in Toronto, Ontario (July 10-13).

For instance, an effort by the Chinese government to reform hospitals by eliminating user fees faces tough opposition from clinicians. Also stymied - by a lack of physicians and money to pay them - is an effort to extend access to basic health care to 800 million rural residents, many of whom live in poverty.

At a special forum on the progress of the reforms, Tsung-Mei Cheng, a health policy research analyst at Princeton University in New Jersey, said the fact that hospitals continue to derive almost $40 \%$ of their income from user fees confounds efforts to reduce the financial burden of health care for the poor.

"In some areas, the out-of-pocket costs of inpatient care have risen despite increased insurance from government, which suggests it didn't make a difference," she told the congress. "Hospitals and doctors help themselves by doing all sorts of additional tests and treatments."

The government, Cheng said, "is painfully aware of these problems." In recent weeks, she noted, it has increased pressure to eliminate user fees and force the adoption of evidence-based clinical processes designed to detect billpadding through inappropriate treatments. On June 22, China's State Council announced a plan to improve medical care by raising education standards for general practitioners and vastly increasing the number of physicians.

The current drive to eliminate user fees would create a system similar to the

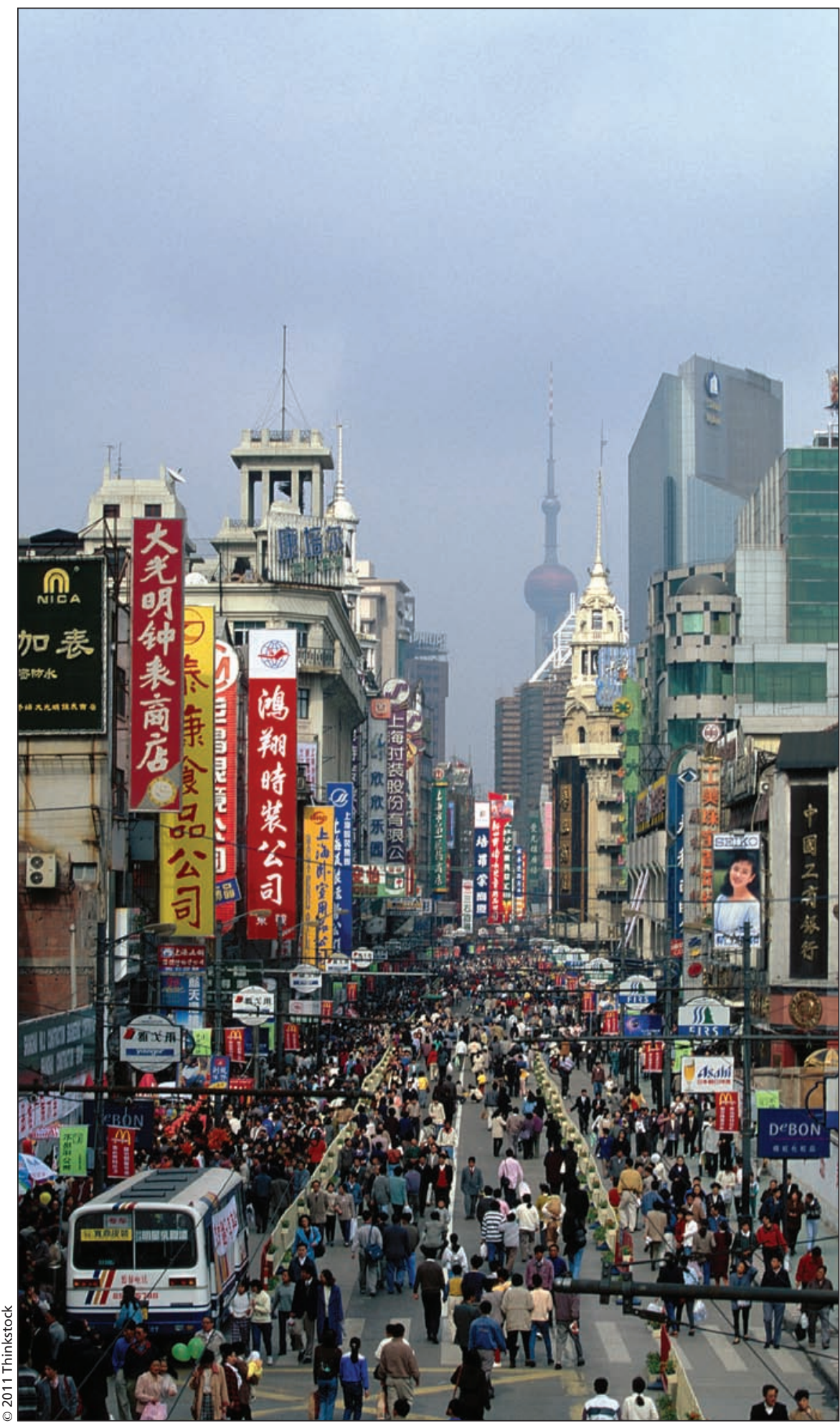

People from Shanghai have incomes ten times higher, on average, than those from China's poorest rural communities, a disparity that is reflected in the quality of health care available in urban and rural areas. 
one that existed before China liberalized its economy in the 1980s, according to Cheng. "In the 1980s, a public hospital was actually public," she said. "But they found it very easy to make money."

Not all observers said the strategy to reimpose a publicly financed system makes sense. At a special forum on private-sector health financing, World Bank economist Xiaohui Hou described the public elements of the Chinese system as "too expensive and too inaccessible." Beijing needs to rethink its vow to reimpose public control over the hospital sector, Hou suggested, claiming there was "no evidence that private, for-profit hospitals drive up average medical expenditures while serving their profit-maximization objectives. Rather, they help increase the market supply of health care, which in turn better serves the increasing demand."

Other observers, however, said the need for reform has been evident for years, noting that health care costs have increased $18 \%$ annually and, because government spending hasn't kept pace, about $60 \%$ of spending on health comes from patients' pockets.

To address these and other problems, China's government claims it has already extended health insurance coverage to $96 \%$ of the population and that more than 5000 new clinics have been built, though numerous observers said the reforms have yet to reduce the vast disparity in the quality of health care available to rural and urban residents.

Perhaps this isn't surprising, considering that the average income in the country's richest city, Shanghai, is 10 times higher than in China's poorest rural areas, noted Yu Wei, an economics professor at China's Shanghai University. "This regional disparity is the central problem in reforming health care," Wei told the conference.

To redistribute resources from the country's wealthy cities into rural regions, Wei argued, the government has limited options. "You cannot do these reforms by cutting doctors' incomes. But increases in prices are not feasible either." In the end, Wei suggested, the success of the reforms will hinge on the government's ability to improve care in deprived regions and finance it through forcing savings in rich regions. - Paul Christopher Webster, Toronto, Ont.

CMAJ 2011. DOI:10.1503/cmaj.109-3949 